\title{
Antifungal Activity of Polyscias scutellaria Fosberg Leaves Against Candida albicans
}

\author{
Nada Marcha Putri ${ }^{1}$, Jasmine Regita Putri ${ }^{1}$, Berna Elya ${ }^{*}$, Robiatul Adawiyah ${ }^{1,2}$ \\ ${ }^{1}$ Faculty of Pharmacy, Universitas Indonesia, Depok, West Java, Indonesia \\ ${ }^{2}$ Department of Parasitology, Faculty of Medicine, Universitas Indonesia, Depok, West Java, Indonesia
}

\begin{abstract}
Polyscias scutellaria Fosberg is one of the indigenous plants from Indonesia that widely used as folk medicines for several illnesses. The leaves of $P$. scutellaria were previously studied as an antimicrobial agent. Nonetheless, this theory of antifungal activity has never been scientifically verified. This study aimed to evaluate the antifungal activity of $P$. scutellaria against Candida albicans. The leaves of $P$. scutellaria were macerated using an ethanol solvent. Then, the extract was evaporated and dissolved by $1 \%$ DMSO into different concentrations $(100 \mu \mathrm{g} / \mathrm{mL}, 200 \mu \mathrm{g} / \mathrm{mL}, 400 \mu \mathrm{g} / \mathrm{mL}, 800 \mu \mathrm{g} / \mathrm{mL}, 1600$ $\mu \mathrm{g} / \mathrm{mL}, 3200 \mu \mathrm{g} / \mathrm{mL}$, and $6400 \mu \mathrm{g} / \mathrm{mL}$ ). Fluconazole, as a common antifungal treatment, was used as the positive control. The antifungal activity of $P$. sculletaria against Candida albicans was tested using well dilution and diffusion disc methods. Ethanol extract of $P$. scutellaria leaves showed antifungal activities against Candida albicans. It showed the minimum inhibitory concentration of above 6400 $\mu \mathrm{g} / \mathrm{mL}$ and formed the inhibitory zone against Candida albicans. As a conclusion, ethanol extract of P. scutellaria has the potential to be used as an antifungal agent against Candida albicans.
\end{abstract}

Keywords: Candida albicans; antifungal; Polyscias scutellaria; well dilution; disc diffusion

*corresponding author

Email: berna.elya@farmasi.ui.ac.id

\section{INTRODUCTION}

Indonesia is rich in biodiversity and is also known as a mega diversity country. Indonesian biodiversity has been utilized to support livelihoods, especially for food, health and energy that aim to meet human necessities. It provides plants that can be used to develop herbal medicine. In fact, many Indonesian people depend on nature to treat illness. In prior study, plants are rich in a wide variety of secondary metabolites that have antimicrobial properties (Dahanukar et al., 2000). One plant that has the potential to be used as a medicinal plant is the leaf of P. scutellaria. Its leaf is mostly used traditionally to treat breast inflammation, wound, urinary tract problems, and body odor (Rosa et al., 2019). Based on the previous study P. scutellaria leaves have antibacterial properties. The leaves contain alkaloid, saponin, tannin, and flavonoid. The most bioactive compound contained in P. scutellaria is alkaloid that is used to bother the stability of peptidoglycan and degrade the fungal cell walls. Another active compound is triterpenoid saponins, which is widely known as one of the antifungal materials from natural herb plants (Arif, Bhosale, \& Kumar, 2009).

Polymorphic yeast, like C. albicans, is part of normal flora in the human body. In some cases, C. albicans can cause several infections, starting from superficial infections on the skin to systemic infections. The growth of the yeast can be inhibited by the antifungal agent presence. Therapy for candidiasis can be carried out by using topical antifungal agents and oral antifungal agents from azole classes (Katzung, 2010). The type of azole antifungal works by inhibiting $14 \alpha$-lanosterol demethylase in the ergosterol synthesis pathway (Ghannoum \& Rice, 1999). Fluconazole is one of the antifungal agents against most isolates of Candida (Lyon, Karatela, \& Sunay, 2010). Recently, many researchers go over the case to investigate traditional medicine. Therefore, based on the benefits of P. scutellaria leaves, this study aims to determine the activity of ethanol extract of $P$. scutellaria leaves on the $C$. albicans as the cause of several infections. This research can be a start line for antifungal activity study in P. scutellaria leaves. Our aim of this study was to identify antifungal activity, which is expected from the presence of the active compound that is contained in P. scutellaria leaves.

\section{METHODS}

\section{Sample Preparation}

First, the leaves were cleaned and rinsed with water. Afterward, the leaves of $P$. scutellaria were dried for preparation of the plant extract in the oven within the temperature of $50{ }^{\circ} \mathrm{C}$. The leaves of $P$. scutellaria were collected from Lenteng Agung Area, South Jakarta, Indonesia. For the extract preparation, $50 \mathrm{~g}$ of dry powder of the leaves were placed in a $1000 \mathrm{~mL}$ of Erlenmeyer 
containing $500 \mathrm{~mL}$ of ethanol solvent. The content in the Erlenmeyer was mixed at first with stirrer stick and being macerated for 24 hours at room temperature. The extract was then filtered using Whatman ${ }^{\circledR}$ paper No.2 (Cat. Number: 28419866, Sigma-Aldrich, USA) Then, the solvent was evaporated by using a rotary evaporator and vacuum (Buchi R-205 and V-500) at temperature 60 ${ }^{\circ} \mathrm{C}$. The obtained extract was weighed for $16 \mathrm{mg}$ and dissolved in $10 \mathrm{~mL} 1 \%$ DMSO.

\section{Preparation/Inoculation of Candida albicans}

Candida albicans were obtained from Parasitology Laboratory, Faculty of Medicine Universitas Indonesia (FMUI). The yeast colony was suspended in $10 \mathrm{~mL}$ tube containing $\mathrm{NaCl}$ solution $(0,85 \%)$ in a tube. Then, the turbidity was equalized to the standard of $0,50 \mathrm{McF}$ arland (as many as $0,4 \times 10^{6}-5 \times 10^{6} \mathrm{CFU} / \mathrm{mL}$ colonies) using the Densichek.

\section{Disc Diffusion Method}

The disc diffusion method is the most widely used method for determining antifungal activity. Extracts of P. scutellaria were prepared in the concentration of 100 , 200, 400, 800 and $1600 \mu \mathrm{g} / \mathrm{mL}$, respectively. The blank discs were moistened by $200 \mu \mathrm{L}$ extract solution of each concentration. Afterward, C. albicans was smeared on the Sabouraud Dextrose Agar (SDA) growth medium and the discs were put on. Triplicate repetitions have been done for each concentration. Then, the Petri dishes were incubated for 24 hours at $37^{\circ} \mathrm{C}$ and diameter of the clear zone was measured. As a negative control, $20 \mu \mathrm{L}$ of $1 \%$ DMSO was used, while the positive control was $20 \mu \mathrm{L}$ of $0,1 \mathrm{mg} / 10 \mathrm{ml}$ fluconazole. The result of this method was interpreted statistically by using one-way Anova.

\section{Well Dilution Method}

The experimental group was divided into five groups: positive control, negative control, media control, growth control, and treatment control. MIC determination was carried out using a microplate. Microplate consists of 96 wells consisting of twelve columns and 8 rows. The first column until the fifth column were filled by $50 \mu \mathrm{L}$ of yeast suspension and $50 \mu \mathrm{L}$ of RPMI medium respectively. Then, $50 \mu \mathrm{L}$ of fluconazole solution was pipetted into A1 well. Following that, $50 \mu \mathrm{L}$ of fluconazole was pipetted from the first column and transferred to the second column well and so on until the fifth well. In the sixth column well was filled with 150 $\mu \mathrm{L}$ water for injection as a negative control with yeast suspension and RPMI medium (ratio 1:1:1). The seventh column well was filled by $150 \mu \mathrm{L}$ suspension of DMSO solution with yeast suspension and RPMI medium. In the eighth column well, $50 \mu \mathrm{L}$ of yeast suspension and 50 $\mu \mathrm{L}$ of RPMI medium were added. The ninth column well was filled with RPMI medium only. In the first to fifth columns in the second row, $50 \mu \mathrm{L}$ of fungal suspension and $50 \mu \mathrm{L}$ of RPMI medium were added. A total of 50 $\mu \mathrm{L}$ of the sample on the first well in the second row was inserted, then mixed. Next, $50 \mu \mathrm{L}$ was pipetted to the second column well in the second row and so on until the fifth well in the second row. All experimental groups were carried out in triplicate. Microplate then incubated at $35^{\circ} \mathrm{C}$ in $48 \mathrm{~h}$. Then, $50 \mu \mathrm{L}$ mixed solution from each well was transferred onto Sabouraud Dextrose Agar medium. The result could be read after 48 hours of incubation.

\section{Data Analysis.}

We use One-way Anova statistical method by Microsoft Excel for data analysis.

\section{RESULTS AND DISCUSSION}

In this study, the leaf extract of Polyscias scutellaria Fosberg exhibited inhibitory activity against $C$. albicans. The yeast of $C$. albicans was obtained from the laboratory of Parasitology, Universitas Indonesia. It was assessed using two different methods. The diffusion disc method was done to exhibit the clear zone of ethanol

Table 1. Results of diffusion disc method

\begin{tabular}{|c|c|c|c|c|c|}
\hline \multirow{2}{*}{ No } & \multirow{2}{*}{ Sample } & \multicolumn{3}{|c|}{ Clear Zone Diamater (mm) } & \multirow{2}{*}{ Average \pm SD } \\
\hline & & 1 & 2 & 3 & \\
\hline 1 & Standard & 2 & 2 & 2 & 2 \\
\hline 2 & $1 \% \mathrm{DMSO}$ & 0 & 0 & 0 & 0 \\
\hline 3 & Extract $100 \mu \mathrm{g} / \mathrm{mL}$ & 3 & 3.1 & 2 & $2 \pm 0.37$ \\
\hline 4 & Extract $200 \mu \mathrm{g} / \mathrm{mL}$ & 4 & 2.8 & 1.35 & $2.72 \pm 1.76$ \\
\hline 5 & Extract $400 \mu \mathrm{g} / \mathrm{mL}$ & 2 & 3.1 & 1.35 & $2.15 \pm 0.78$ \\
\hline 6 & Extract $800 \mu \mathrm{g} / \mathrm{mL}$ & 2 & 3 & 1.45 & $2.15 \pm 0.61$ \\
\hline 7 & Extract $1600 \mu \mathrm{g} / \mathrm{mL}$ & 2 & 3.35 & 2.7 & $2.68 \pm 0.46$ \\
\hline
\end{tabular}


Table 2. Results of optical density (ELISA) readings of Well-dilution method

\begin{tabular}{lllllll}
\hline & Standard & Extract 1 & Extract 2 & Extract 3 & Extract 4 & Extract 5 \\
\hline Repetition 1 & 0.2994 & 0.3563 & 0.3612 & 0.3442 & 0.3485 & 0.3521 \\
Repetition 2 & 0.307 & 0.3435 & 0.3627 & 0.3351 & 0.3348 & 0.3371 \\
Repetition 3 & 0.3365 & 0.3494 & 0.3559 & 0.3569 & 0.3647 & 0.3466 \\
Mean \pm SD & $0.3143 \pm$ & $0.350 \pm$ & $0.360 \pm$ & $0.345 \pm$ & $0.349 \pm$ & $0.345 \pm$ \\
& 0.0003 & 0.00004 & 0.00001 & 0.0001 & 0.0002 & 0.00005 \\
\hline
\end{tabular}

Notes:

Extract $1=400 \mu \mathrm{g} / \mathrm{mL}$

Extract $2=800 \mu \mathrm{g} / \mathrm{mL}$

Extract $3=1600 \mu \mathrm{g} / \mathrm{mL}$

Extract $4=3200 \mu \mathrm{g} / \mathrm{mL}$

Extract $5=6400 \mu \mathrm{g} / \mathrm{mL}$

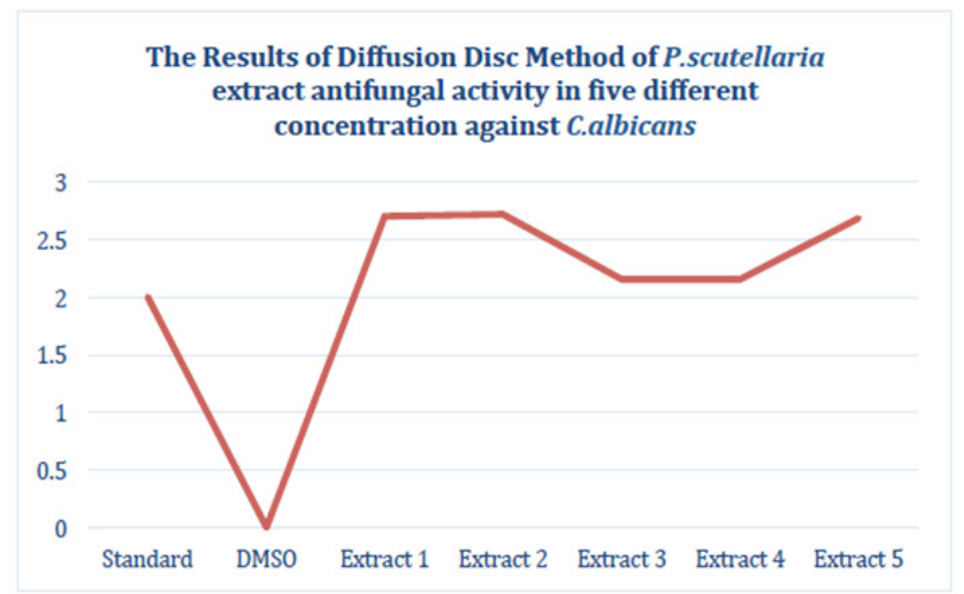

Figure 1. Results of diffusion disc method of P. scutellaria extract antifungal activity in five different concentrations against $C$. albicans

extract of $P$. scutellaria leaves. The concentrations of the extracts were varied into five different concentrations. Then, the experiment was repeated three times for each concentration.

As shown in Figure 1, all concentrations of the extract performed clear zone diameters representing that indicate the antifungal activity of $P$. scutellaria leaves. The development of a disk diffusion-based assay is desirable for determining the antifungal susceptibility of dermatophytes based on the advantages (Nweze, Mukherjee, \& Ghannoum, 2010). Clear zone diameter of the diffusion disc method could strongly indicate the strength of antifungal activities of the extract against $C$. albicans. As the concentration lower, it exhibited smaller clear zones, which means there was no antifungal activity (Rosa et al., 2019). The clear zone diameters for different five concentrations have statistically verified to be significantly different by observing that p-value was lower than 0.05 , the result showed 0.007 .
The result diffusion disc was tested statistically by oneway Anova method. It can be verified by comparing the value of $\mathrm{F}$ with $\mathrm{F}$-crit. The result showed that the value of $\mathrm{F}$ was higher than $\mathrm{F}$-crit, it describes that the hypothesis of this experiment is accepted. This statistical result indicates that the clear zone diameters of ethanol extract of $P$. scutellaria were significantly different in each concentration.

An experiment was done in this research using fluconazole as a positive control and the clear zone was formed less than $10 \mathrm{~mm}$, showing that $C$. albicans susceptibility to fluconazole. This indicated that $P$. scutellaria extracts have the possibility to become an alternative antibacterial agent against $C$. albicans. Furthermore, to measure the capability of each concentration in inhibiting the growth of Candida albicans by knowing the Minimum Inhibitory Concentration of the extract, a Well-Diluted method of analysis was performed. The result was depicted in Figure 2. In the dilution method analysis, The culturing 


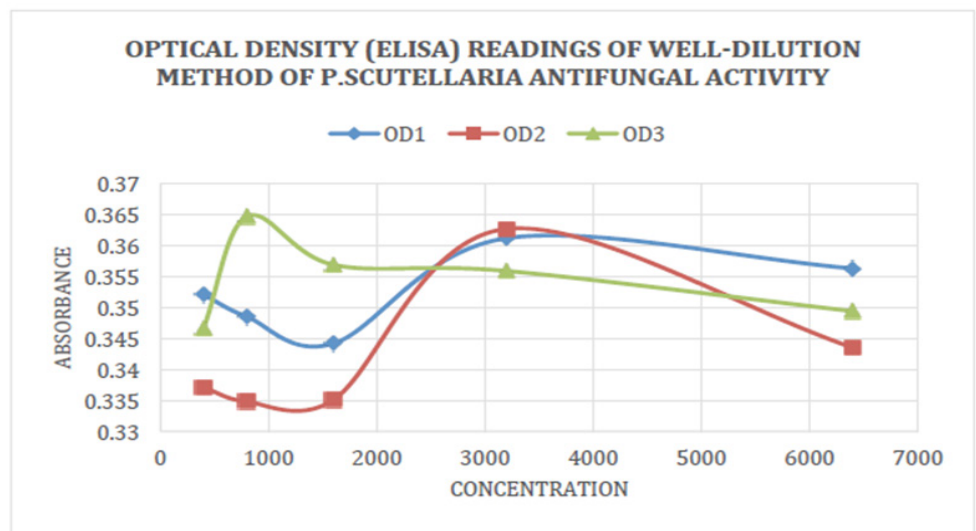

Figure 2. Results of optical density (ELISA) readings of $P$. scutellaria extract inhibiting the growth of $C$. albicans by Well-dilution method

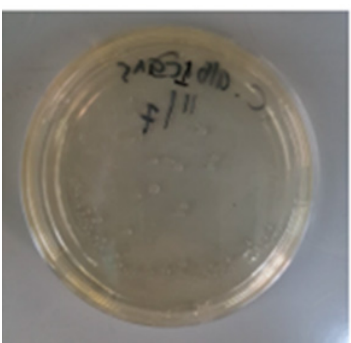

Figure 3. Visualization of fluconazole as a positive control

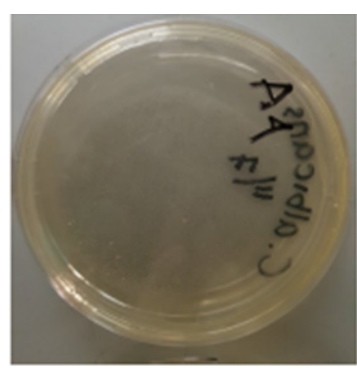

Figure 6. Visualization of $P$. scutellaria leaves extract in $1600 \mu \mathrm{g} / \mathrm{mL}$ concentration

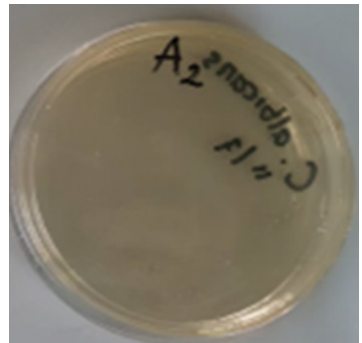

Figure 4. Visualization of $P$. scutellaria leaves extract in $400 \mu \mathrm{g} / \mathrm{mL}$ concentration

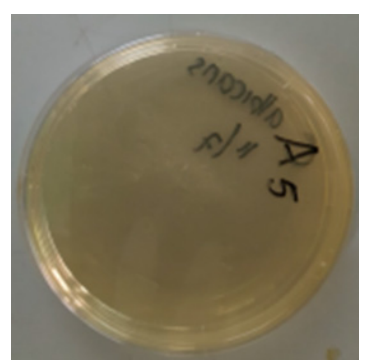

Figure 7. Visualization of $P$. scutellaria leaves extract in $3200 \mu \mathrm{g} / \mathrm{mL}$ concentration

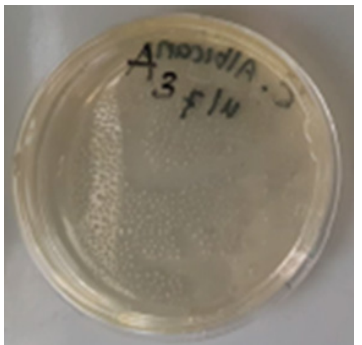

Figure 5. Visualization of $P$. scutellaria leaves extract in $800 \mu \mathrm{g} / \mathrm{mL}$ concentration

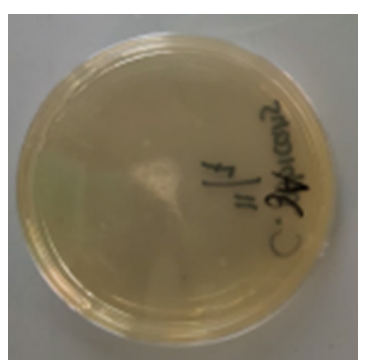

Figure 8. Visualization of $P$. scutellaria leaves extract in $6400 \mu \mathrm{g} / \mathrm{mL}$ concentration from wells was conducted to find concentrations that can inhibit the growth of $C$. albicans yeast. Fungal colonies that grow on fluconazole are very few. The results of cultured extracts showed that the MIC of ethanol extract of the P. scutellaria leaves was above $6400 \mu \mathrm{g} / \mathrm{mL}$. The inhibition of C.albicans was caused by alkaloids that are used to interfere the stability of peptidoglycan and degrade the fungal cell walls. Another active compound is triterpenoid saponins which is known as an antifungal activity compound. Those are contained in P. scutellaria leaves (Arif, Bhosale, \& Kumar, 2009).

The results were statistically tested using one-way anova. The turbidity of five different concentrations has also statistically verified to be different by looking at $\mathrm{p}$-value which is lower than 0.05 , the result showed 0.009 . It means that there is no significant difference of the turbidity in the wells of each concentration and controls.

Furthermore, the growth of C. albicans colonies could be seen by visual readings, as shown in figure 3 until Figure 8 . The culture medium that was used for smearing the sample was Sabouraud Dextrose Agar. The result after 24 hours of incubation showed that in the highest concentration, the growth of $C$. albicans colonies could be inhibited. A reference microdilution method was approved by the Clinical and Laboratory Standards Institute (CLSI) for antifungal susceptibility testing of molds and dermatophytes. 


\section{CONCLUSION}

The result showed as the concentration of $P$. scutellaria leaf extract went higher the number of $C$. albicans colonies was decreased. It showed that $6400 \mu \mathrm{g} / \mathrm{mL}$ was the highest concentration that significantly decreased the growth of $C$. albicans colonies. However, further studies are required to better evaluate the potential effectiveness of the crude extracts as antimicrobial agents.

\section{ACKNOWLEDGMENT}

The authors of this paper acknowledge Universitas Indonesia for the invaluable support and for providing all the research facilities. The authors also acknowledge the laboratory of Parasitology, Universitas Indonesia, Depok, Indonesia, for helping and providing necessary facilities for this research.

\section{REFERENCES}

Arif, T., Bhosale, J. D., \& Kumar, N. (2009). Natural products - Antifungal agents derived from plants. (July). https://doi.org/10.1080/10286020902942350

Ashmawya, N. S., Gad, H. A., Ashoura, M. L., Elahmadya, S. H., \& Singab, A. N. B. (2018). Comparative Study on the Volatile Constituents of Polyscias guilfoylei and Polyscias balfouriana Leaves Medicinal \& Aromatic Plants. 7(6). https://doi.org/10.4172/21670412.1000321

Balouiri, M., Sadiki, M., \& Ibnsouda, S. K. (2016). Methods for in vitro evaluating antimicrobial activity: A review. Journal of Pharmaceutical Analysis, 6(2), 7179. https://doi.org/10.1016/j.jpha.2015.11.005

Dagi, H. T., Findik, D., Senkeles, C., \& Arslan, U. (2016). Identification and antifungal susceptibility of Candida species isolated from bloodstream infections in Konya, Turkey. Annals of Clinical Microbiology and Antimicrobials, 1-5. https://doi.org/10.1186/s12941016-0153-1

Ghannoum, M. A., \& Rice, L. B. (1999). Antifungal Agents : Mode of Action, Mechanisms of Resistance , and Correlation of These Mechanisms with Bacterial Resistance. 12(4), 501-517.
Lunga, P. K., Qin, X., Yang, X. W., Kuiate, J., Du, Z. Z., \& Gatsing, D. (2014). Antimicrobial steroidal saponin and oleanane-type triterpenoid saponins from Paullinia pinnata. 2, 1-7.

Lyon, G. M., Karatela, S., \& Sunay, S. (2010). Antifungal Susceptibility Testing of Candida Isolates from the Candida Surveillance Study. 48(4), 1270-1275. https:// doi.org/10.1128/JCM.02363-09

Nweze, E. I., Mukherjee, P. K., \& Ghannoum, M. A. (2010). Agar-based disk diffusion assay for susceptibility testing of dermatophytes. Journal of Clinical Microbiology, 48(10), 3750-3752. https://doi. org/10.1128/JCM.01357-10

Prince, R. L. (1996). Practice guidelines for the treatment of osteoporosis. Calcified Tissue International, 59(SUPPL. 1), 3-13. https://doi.org/10.1007/ s002239900171

Rex, J. H., Walsh, T. J., Sobel, J. D., Filler, S. G., Pappas, P. G., Dismukes, W. E., \& Edwards, J. E. (n.d.). Practice Guidelines for the Treatment of Candidiasis. (Table 1), 3-13.

Rosa, D., Halim, Y., Kam, N., Sugata, M., \& Samantha, A. (2019). Antibacterial Activity of Polyscias scutellaria Fosberg Against Acenobacter SP. 12(1), 0-3.

Santos, G. C. d. O., Vasconcelos, C. C., Lopes, A. J. O., Cartágenes, M. do S. d. S., Filho, A. K. D. B., do Nascimento, F. R. F., ... Monteiro, C. de A. (2018). Candida infections and therapeutic strategies: Mechanisms of action for traditional and alternative agents. Frontiers in Microbiology, 9(JUL), 1-23. https:// doi.org/10.3389/fmicb.2018.01351

Yang, C., Zhang, Y., Jacob, M. R., Khan, S. I., \& Zhang, Y. (2006). Antifungal Activity of C-27 Steroidal Saponins. 50(5), 1710-1714. https://doi.org/10.1128/ AAC.50.5.1710 